\title{
Occurrence of autoimmune pancreatitis after chronic immune thrombocytopenia in a Caucasian adolescent
}

\author{
Hubert Kogler ${ }^{1}\left[\right.$. Wolfgang Novak ${ }^{1} \cdot$ Andreas Vécsei $^{1} \cdot$ Christina Zachbauer $^{2} \cdot$ Wolf-Dietrich Huber $^{2}$. \\ Karoly Lakatos ${ }^{1} \cdot$ Katharina Woeran $^{3} \cdot$ Judith Stift ${ }^{3} \cdot$ Kaan Boztug $^{1,4,5,6} \cdot$ Leo Kager $^{1,4}$
}

Received: 30 January 2021 / Accepted: 8 March 2021 / Published online: 20 March 2021

(c) The Author(s) 2021

\begin{abstract}
Autoimmune pancreatitis is a rare, distinct and increasingly recognized form of chronic inflammatory pancreatic disease secondary to an underlying autoimmune mechanism. We report on a 14-year-old boy who developed autoimmune pancreatitis, while he was under treatment with eltrombopag for chronic immune thrombocytopenia. Therapy with corticosteroids resulted in complete remission of both. This is the first report on the co-occurrence of autoimmune pancreatitis and chronic immune thrombocytopenia in childhood, and clinicians should be aware of this rare association, because early diagnosis and therapy of autoimmune pancreatitis may prevent severe complications.
\end{abstract}

Keywords Autoimmune pancreatitis $\cdot$ Immune thrombocytopenia $\cdot$ Pancreas $\cdot$ Hematology $\cdot$ Immunology

\section{Introduction}

Immune thrombocytopenia (ITP) is an acquired bleeding disorder, caused by autoimmune-mediated destruction of platelets and megakaryocytes [1]. In pediatrics, ITP generally has a good prognosis and is spontaneously resolving in $70-80 \%$ of patients. However, in some patients, severe bleedings and a chronic course can occur [1]. In addition, ITP can be complicated by the co-occurrence of other autoimmune diseases, such as autoimmune thyroiditis, celiac disease, systemic lupus erythematosus, autoimmune hepatitis, and other autoimmune cytopenias [2-5].

Leo Kager

leo.kager@stanna.at

1 Department of Pediatrics and Adolescent Medicine, St. Anna Children's Hospital, Medical University Vienna, Kinderspitalgasse 6, 1090 Vienna, Austria

2 Department of Pediatric Nephrology and Gastroenterology, Medical University Vienna, Vienna, Austria

3 Department of Pathology, Medical University Vienna, Vienna, Austria

4 Children's Cancer Research Institute, Vienna, Austria

5 Ludwig Boltzmann Institute for Rare and Undiagnosed Diseases, Vienna, Austria

6 CeMM Research Center for Molecular Medicine of the Austrian Academy of Sciences, Vienna, Austria
Within the spectrum of autoimmune diseases, autoimmune pancreatitis (AIP) is increasingly recognized as a distinct entity. AIP is characterized by abdominal pain, obstructive jaundice, pancreatic parenchymal changes caused by lymphoplasmacytic infiltration, and a prompt clinical response to steroid therapy $[6,7]$. AIP is extremely rare in children, with only about 50 patients described so far [6, 8]. Of note, $\sim 27 \%$ of these have been reported to additionally suffer from other autoimmune diseases [6, 7]. However, the co-occurrence of ITP and AIP in childhood has not been reported before.

\section{Case report}

ITP first manifested in the Caucasian male patient at the age of 11 years. He was admitted due to signs of bleeding and laboratory tests revealed severe isolated thrombocytopenia (platelet count $3 \times 10^{9} / \mathrm{L}$ ). Pertinent diagnostic data are provided in Table 1. Except for elevated anti-nuclear antibodies (ANA 1:640, normal negative), no abnormalities were found, and a diagnosis of ITP was made. While repetitive treatments with IVIG $(0.8 \mathrm{~g} / \mathrm{kg})$ and a short course of corticosteroids resulted in transiently increased platelet counts $\left(>100 \times 10^{9} / \mathrm{L}\right)$, he failed, however, in achieving a stable remission. During each relapse, platelet count was $<10 \times 10^{9} / \mathrm{L}$ with the presence of cutaneous and/or 
Table 1 Diagnostic work-up and results for chronic immune thrombocytopenia (cITP) and autoimmune pancreatitis (AIP)

\begin{tabular}{|c|c|}
\hline Diagnostics & Results (normal values) \\
\hline \multicolumn{2}{|l|}{ Chronic immune thrombocytopenia } \\
\hline \multicolumn{2}{|l|}{ Humoral (auto-)immunity } \\
\hline Anti-platelet antibodies & Negative \\
\hline $\begin{array}{l}\text { Nuclear antibodies: ANA, DNA, SM, RNP, RO, LA, SCL, JO, } \\
\text { HIST, NUC, ACENA }\end{array}$ & ANA 1:640 (negative), all others negative \\
\hline $\begin{array}{l}\text { Antiphospholipid antibodies: CARG, CARA, B2GPG, B2GPA, } \\
\text { B2GPM }\end{array}$ & Negative \\
\hline Mannan binding lectin, complement analyses $(\mathrm{C} 3, \mathrm{C} 4)$ & Normal \\
\hline Immunoglobulins: IgG, IgM, IgA, IgG1, IgG2, IgG3, IgG4 & Normal \\
\hline \multicolumn{2}{|l|}{ Cellular immunity (flow cytometry) } \\
\hline $\begin{array}{l}\text { T-cells: CD3, CD4/3, CD8/3, CD4/8, HLA-D3, CD25/3, Ta/b, } \\
\text { Tg/d, 45RA/45R0, 45R0/45RA, 4/45RA, 4/45R0, 8/45RA, } \\
\text { 8/45R0, 45RA/62L/8, 3/127, 3/132, 3/154, DNT }\end{array}$ & T cells and subtypes: normal \\
\hline B-cells: CD19, IgD +/CD27 +, IgD-/CD27 +, CD21 & B cells and subtypes: normal \\
\hline NK-cells: CD56/3 & NK-cells: normal \\
\hline $\begin{array}{l}\text { Lymphocyte function testing: CD3, SEA and TT induced prolifera- } \\
\text { tion }\end{array}$ & Normal \\
\hline \multicolumn{2}{|l|}{ Bone marrow failure or myelodysplasia/leukemia } \\
\hline Cytogenetics, diepoxybutan testing & 46, XY[10], normal \\
\hline FLOW & No leukemic cells detectable \\
\hline $\begin{array}{l}\text { FISH-MDS (monosomy } 7 \text {, trisomy } 8 \text {, monosomy } 5 \text {, deletion } 5 \mathrm{q} \text {, } \\
\text { deletion } 7 \mathrm{q} \text { ) }\end{array}$ & No MDS typical chromosomal anomalies detectable \\
\hline Bone marrow analysis (Giemsa staining) & $\begin{array}{l}\text { Normal cellularity except for increased number of megakaryocytes, } \\
\text { compatible with ITP }\end{array}$ \\
\hline \multicolumn{2}{|l|}{ Infection diseases } \\
\hline $\begin{array}{l}\text { Virus nucleic acid testing via PCR in bone marrow/plasma: CMV, } \\
\text { PVB19, AdV A/B/C/D/E/F/G, EBV }\end{array}$ & Negative \\
\hline Helicobacter pylori (PCR stool) & Negative \\
\hline HIV serology & Negative \\
\hline $\begin{array}{l}\text { Hepatitis serology: anti-HAV IgG, anti-HAV IgM, HBsAg, anti- } \\
\text { HBc IgG, anti-HBc IgM }\end{array}$ & $\begin{array}{l}\text { All negative except for anti-HAV IgG } 4 \text { IU/l (negative) and anti- } \\
\mathrm{HbSAg}>1000 \mathrm{IU} / 1\end{array}$ \\
\hline \multicolumn{2}{|l|}{ Other autoimmune diseases } \\
\hline Thyroid hormones (TSH, fT4) & Normal \\
\hline Celiac disease serology & Normal \\
\hline \multicolumn{2}{|l|}{ Autoimmune pancreatitis } \\
\hline Pancreas function testing: serum or stool analyses & $\begin{array}{l}\text { Amylase } 395 \mathrm{U} / \mathrm{L}(28-100 \mathrm{U} / \mathrm{L}) \text {, lipase } 1262 \mathrm{U} / \mathrm{L}(7-39 \mathrm{U} / \mathrm{L}), \mathrm{HbA} 1 \mathrm{c} \\
5,4 \%(4-6 \%) \text {, OGTT normal, elastase }<50 \mu \mathrm{g} / \mathrm{g} \text { stool }\end{array}$ \\
\hline Liver function testing: serum analyses & $\begin{array}{l}\text { GGT } 773 \mathrm{U} / \mathrm{L}(<52 \mathrm{U} / \mathrm{L}), \text { ALT } 453 \mathrm{U} / \mathrm{L}(0-31 \mathrm{U} / \mathrm{L}), \text { AST } 247 \mathrm{U} / \mathrm{L} \\
(0-34 \mathrm{U} / \mathrm{L}), \text { ALP } 947 \mathrm{U} / \mathrm{L}(<390 \mathrm{U} / \mathrm{l}), \mathrm{TBIL} 3.1 \mathrm{mg} / \mathrm{dl}(0-1 \mathrm{mg} / \mathrm{dl}) \text {, } \\
\text { BC } 2,76 \mathrm{mg} / \mathrm{dl}(0-0.25 \mathrm{mg} / \mathrm{dl}), \mathrm{TP} 58,7 \mathrm{~g} / \mathrm{L}(60-80 \mathrm{~g} / \mathrm{L}), \text { PRALB } \\
19 \mathrm{mg} / \mathrm{dl}(12-42 \mathrm{mg} / \mathrm{dl})\end{array}$ \\
\hline Tumor marker: Serum analyses & $\begin{array}{l}\text { CA 19-9 30.1 kU/L (0-27 kU/L), CEA } 0.8 \mu \mathrm{g} / \mathrm{L}(0-3.8 \mu \mathrm{g} / \mathrm{L}) \text {, NSE } \\
19.6 \mu \mathrm{g} / \mathrm{L}(0-16.3 \mu \mathrm{g} / \mathrm{L})\end{array}$ \\
\hline $\begin{array}{l}\text { Immunology testing: immunoglobulins: IgG, IgM, IgA, IgG1, IgG2, } \\
\text { IgG3, IgG4 }\end{array}$ & IgG 548 mg/dl (698-1194 mg/dl), all others normal \\
\hline $\begin{array}{l}\text { Autoantibodies: ANA, DNA, NUC, ENA subsets (RO, LA, SCL-70, } \\
\text { SM, RNP, Jo-1, centromer B, c-ANCA, p-ANCA, X-ANCA, smooth } \\
\text { muscle, mitochondria, parietal cells, LKM, CARG, CARA, B2GPG, } \\
\text { B2GPA, B2GPM, AMA-M2, SP-100, GP210, LC1, SLA }\end{array}$ & ANA 1:160 (negative), all others negative \\
\hline Imaging: abdominal ultrasonography & $\begin{array}{l}\text { Slightly enlarged liver with normal tissue echogenicity, dilatation of the } \\
\text { intra- and extra-hepatobiliary ducts, and a hypoechoic and enlarged } \\
\text { pancreatic head }\end{array}$ \\
\hline Magnetic resonance cholangiopancreatography & $\begin{array}{l}\text { Abrupt termination of the dilated common bile and pancreatic ducts } \\
\text { caused by a pancreatic 'head mass' }\end{array}$ \\
\hline
\end{tabular}


Table 1 (continued)

\begin{tabular}{ll}
\hline Diagnostics & Results (normal values) \\
\hline $\begin{array}{l}\text { Endoscopic ultrasound (EUS)-guided core biopsy-histopathology: } \\
\text { HE and immunological staining }\end{array}$ & $\begin{array}{l}\text { Marked fibrosis, lymphoplasmacytic infiltration, and destruction of } \\
\text { pancreatic ducts without an increased number of IgG4-positive plasma } \\
\text { cells }\end{array}$ \\
\hline
\end{tabular}

ACENA anti-centromere antibodies, $A d V$ adenovirus, $A L P$ alkaline phosphatase, $A L T$ alanin-aminotransferase, $A M A-M 2$ : anti-mitochondrial antibodies M2, ANA anti-nuclear antibodies, $A N C A$ anti-neutrophil cytoplasmic antibodies, anti-HAV anti-hepatitis A virus antibodies, anti-HBC anti-hepatitis $\mathrm{B}$ core antigen antibodies, $A S T$ aspartate transaminase, $B C$ conjugated bilirubin, $B 2 G P A$ beta-2-glycoprotein-1 IgA antibodies, $B 2 G P G$ beta-2-glycoprotein-1 IgG antibodies, B2GPM beta-2-glycoprotein-1 IgM antibodies, $c$-ANCA cytoplasmic ANCA, CARA: anti-cardiolipin IgA antibodies, $C A R G$ anti-cardiolipin IgG antibodies, CA19-9 cancer antigen 19-9, CD3 CD3 positive T-lymphocytes, CD4/3 CD4 positive T-cell subsets, $C D 4 / 8$ CD4/CD8 ratio, $C D 8 / 3$ CD8 positive T-cell subsets, $C D 19$ B-lymphocytes, $C D 21$ CD21 positive B-cell subsets, $C D 25 / 3$ activated CD25 positive T-cell subsets, CD56/3 CD56 positive CD3 negative NK-cell subsets, $C E A$ carcinoembryonic antigen, $C M V$ cytomegalovirus, $D N T$ TCR alpha/beta positive CD4 negative CD8 negative T-lymphocytes, $D N A$ native/double-stranded deoxyribonucleic acid antibodies, $E B V$ Epstein-Barr virus, ENA extractable nuclear antigens, FISH-MDS fluorescence in situ hybridization-myelodysplastic syndrome, FLOW flow cytometry, fT4 free thyroxine, GGT gamma-glutamyl transpeptidase, GP210 anti-glycoprotein-210 antibodies, HbA1c hemoglobin A1c, HBsAg hepatitis B surface antigen, $H E$ hematoxylin and eosin, HLA-D3 activated HLA-D positive T-cell subsets, HIST anti-histone antibodies, $H I V$ human immunodeficiency virus, $I g D+/ C D 27+\operatorname{IgD}$ positive $\mathrm{CD} 27$ positive memory B-cell subsets, $I g D-/ C D 27+\operatorname{IgD}$ negative CD27 positive memory B-cell subsets, $J O$ anti Jo-1 antibodies, $L A$ anti-La antibodies, $L C 1$ anti-liver cytosol antibodies type 1 , $L K M$ anti-liverkidney microsomal antibodies, $N U C$ anti-nucleosome antibodies, NSE neuron specific enolase, $O G T T$ oral glucose tolerance test, $p$-ANCA perinuclear ANCA, $P C R$ polymerase chain reaction, $P R A L B$ prealbumin, $P V B 19$ parvovirus B19, RNP anti-nuclear ribonucleoprotein antibodies, $R O$ anti-Ro-antibodies, $S C L$ anti-Scl-70 antibodies, SEA staphylococcus enterotoxin a, SLA anti-soluble liver antigen antibodies, SM anti-Smith antibodies, $S P-100$ anti-sp100 antibodies, Ta/b TCR alpha/beta positive T-lymphocytes, TBIL total bilirubin, $T g / d$ TCR gamma/delta positive T-lymphocytes, $T P$ total protein, $T S H$ thyroid stimulating hormone, TT tetanus toxoid, $X$-ANCA atypical ANCA, 3/127 IL-7R alpha-chain positive T-lymphocytes, 3/132 common gamma-chain positive T-lymphocytes, 3/154 CD40L positive T-lymphocytes, 4/45RA CD4 positive naive T-cell subsets, $4 / 45 R 0 \mathrm{CD} 4$ positive memory T-cell subsets, $8 / 45 R A$ CD8 positive naive T-cell subsets, $8 / 45 R 0$ CD8 positive memory T-cell subsets, $45 R A / 45 R 0 \mathrm{CD} 45 \mathrm{RA}$ positive naive T-lymphocytes, $45 R A / 62 \mathrm{~L} / 8 \mathrm{CD} 45 \mathrm{RA}$ positive CD62L positive CD8 positive naive T-lymphocytes, 45R0/45RA CD45R0 positive memory T-lymphocytes

mucous bleedings. 17 months after diagnosis, treatment with eltrombopag was started at a dosage of $50 \mathrm{mg} / \mathrm{day}$. An initial increase of the platelet count to $144 \times 10^{9} / \mathrm{L}$ within 3 weeks led to subsequent dose reductions to a final dose of $25 \mathrm{mg} /$ every second day, which resulted in stable platelet counts ranging between $77 \times 10^{9} / \mathrm{L}$ and $128 \times 10^{9} / \mathrm{L}$ (median $\left.99 \times 10^{9} / \mathrm{L}\right)$.

After 25 months on eltrombopag, routine laboratory tests showed elevated transaminases (Table 1). Despite discontinuing eltrombopag treatment, transaminases further increased and he developed icterus and complained of itching and a mild intermittent abdominal pain. Platelet count remained stable after discontinuation of eltrombopag. Further laboratory tests revealed cholestasis and elevated pancreatic enzymes as well as an impaired exocrine pancreas function, whereas endocrine pancreas function remained normal. Pertinent details on further investigations are provided in Table 1. Abdominal ultrasound evaluations revealed dilatation of the intra- and extra-hepatobiliary ducts and a hypoechoic and enlarged pancreatic head. A capsule-like rim surrounding a pancreatic head mass was seen on magnetic resonance imaging (MRI) and magnetic resonance cholangiopancreatography (MRCP) revealed abrupt termination of the dilated common bile and pancreatic ducts caused by the pancreatic head mass (Fig. 1e, f). These findings were suggestive of AIP and endoscopic ultrasound (EUS)-guided core biopsy of the mass with a 22-gauge needle (EZ Shot 3 Plus, Olympus) revealed marked fibrosis, granulocytic infiltration of duct walls, and, in some sections, a dense infiltrate of predominantly lymphocytes and plasma cells encasing pancreatic ducts (Fig. 1a-d), findings characteristic for AIP in childhood [6, 7]. An additional immunohistochemical staining with antiIgG4 antibody showed scant IgG4-positive plasma cells with one "hot spot" region with $5 \mathrm{IgG} 4$-positive cells/high power field (HPF) and apart from that $0-1 \mathrm{IgG} 4$-positive cells/HPF. Given the adolescent age, the normal serum level of IgG4 (46 mg/dl, reference value $4.9-198.6 \mathrm{mg} /$ $\mathrm{dl}$ ), and the characteristic histologic findings with granulocyte infiltration of duct walls and only scant IgG4-positive cells, a diagnosis of type 2 AIP was established according to the international consensus diagnostic criteria (ICDC) for autoimmune pancreatitis [9]. After thorough immunological investigations including an NGS-based immunology panel screen to rule out a genetically defined immune defect [10], treatment with oral prednisone ( $1 \mathrm{mg} / \mathrm{kg} /$ day $)$ was initiated and tapered slowly over 4 months. Within 1 month, transaminases, pancreatic enzymes, and cholestasis parameters normalized as well as the follow-up MRCP 2 months after diagnosis. Platelet counts remained stable within the normal range since start of AIP therapy. Regular follow-up investigations are performed (currently every 4 months), and complete remission of AIP and cITP was documented 30 months after discontinuation of steroid therapy. 

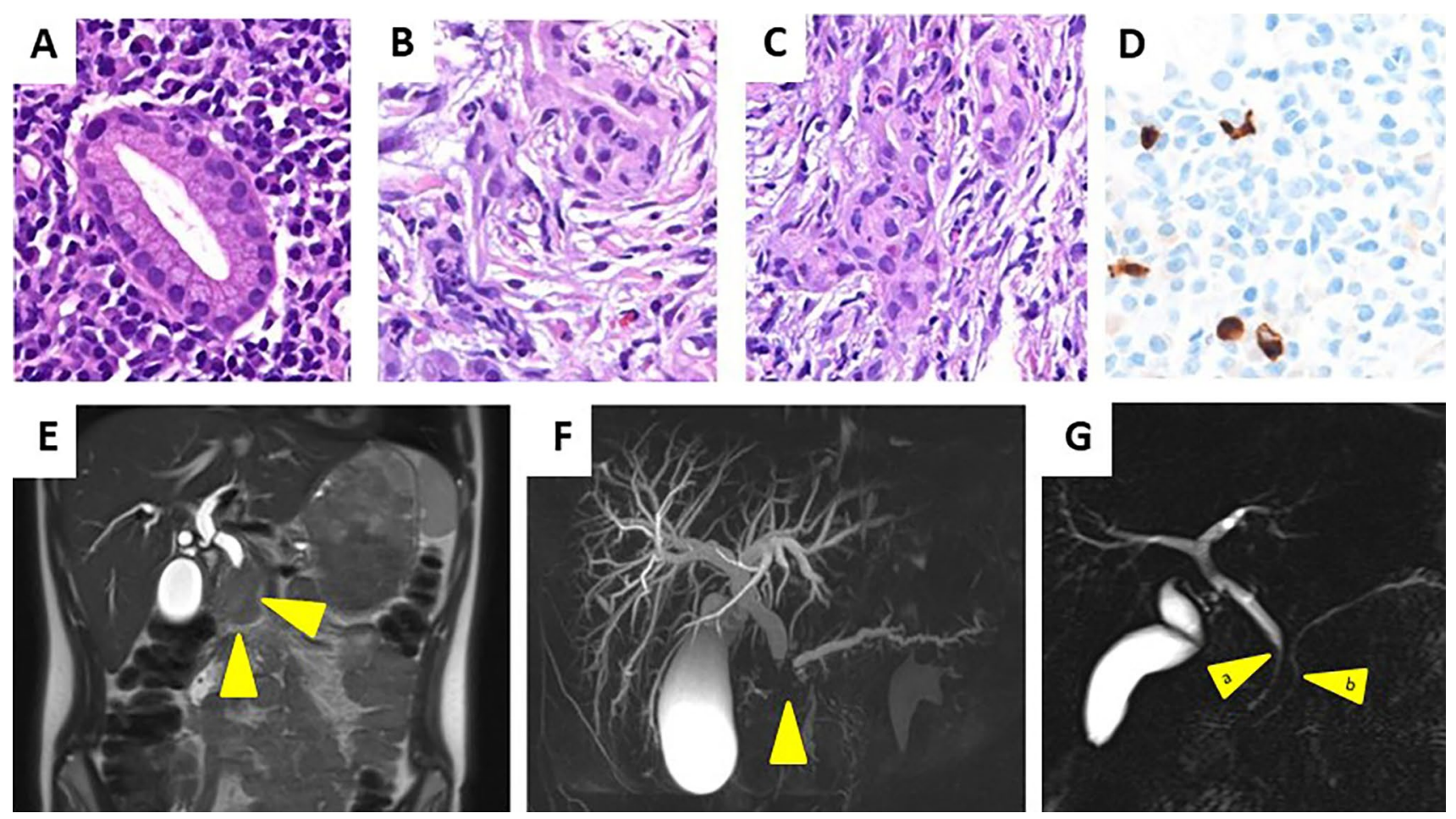

Fig. 1 Histopathologic characteristics and imaging findings of autoimmune pancreatitis in a Caucasian adolescent. Depicted are results from pancreas histopathology (a-d), magnetic resonance imaging (MRI, e), and magnetic resonance cholangiopancreatography (MRCP, f, g). Dense infiltrate of predominantly lymphocytes and plasma cells encases pancreatic ducts (a, hematoxylin and eosin (H\&E) staining, $\times 40)$. Infiltration of the ducts and duct walls by neutrophilic and eosinophilic granulocytes $(\mathbf{b}, \mathbf{c}, \mathrm{H} \& \mathrm{E}, \times 40)$. Only very occasional

\section{Discussion}

Herein, we report for the first time the occurrence of AIP after cITP in childhood. Until now, such an association was reported only in 10 Japanese adults (median age of disease onset 68.5 years, range: $61-80$ years) [11]. In these Asian adults, AIP and ITP occurred concurrently in two patients; in the other patients, ITP always arose after the onset of AIP [median 4 months (range: 10 days to 4 years)]. AIP was recognized to be IgG4-related in all adults where it was measured. IgG4-related disease is a rare immune-mediated disorder characterized by tissue infiltration by IgG4positive plasma cells and elevated serum IgG4 $[11,12]$. In contrast, our Caucasian patient developed AIP at the age of 14 years and neither had an elevated serum IgG4 level, nor an increased number of IgG4-positive plasma cells in the pancreatic biopsy specimen. This is in line with the previous reports, stating that pediatric AIP (p-AIP) is uncommon as part of IgG4-related disease and that children more commonly follow the disease presentation of type 2 AIP [6-8]. According to the ICDC for autoimmune pancreatitis [9], diagnosis of definitive type 2 AIP in our patient was in solitary areas IgG4-positive plasma cells (d, IgG4 immunostaining, $\times 40$ ). Frontal T2-weighted abdominal MRI showed enlargement of the pancreatic head (arrow) (e). MRCP revealed abrupt termination of the dilated common bile duct $(9 \mathrm{~mm})$ and the main pancreatic duct $(4.5 \mathrm{~mm})$ caused by a pancreatic head mass (arrow) (f). The common bile duct (arrow a) and the main pancreatic duct (arrow b) regained its normal caliber within 2 months of steroid therapy (g)

based on the characteristic histology of idiopathic ductcentric pancreatitis in combination with imaging findings of focal enlargement of the pancreatic head with delayed enhancement and a prompt response to a therapy with corticosteroids. P-AIP, however, is commonly associated with other autoimmune/inflammatory diseases, including Crohn's disease, ulcerative colitis, glomerulonephritis, and hemolytic anemia; our observation extends the spectrum to cITP $[6,7]$. Routine immunological testing (Table 1) including a NGS-based immunology panel screen [10] did not reveal obvious pathologies in our patient's immune system except for elevated ANAs and a transient mild decrease of IgG. In patients with p-AIP tested for ANAs, up to $40 \%$ had detectable antibodies [6-8]. Clearly, further investigations and a thorough follow-up for other potential autoimmune manifestations including systemic lupus erythematodes are required in our patient [13].

CITP was successfully treated with eltrombopag, which is an approved cITP medication [14]. Elevations in liver enzymes or bilirubin are known adverse drug effects (ADRs) of eltrombopag [15]. Thus, monitoring of AST, ALT, and bilirubin is mandatory during therapy. In our patient, the 
first signs of AIP were elevated transaminases, which further increased after stop of eltrombopag. Therefore, it is unlikely that eltrombopag was the cause of AIP. However, occurrence of pancreatitis has been reported during eltrombopag treatment in at least two adult patients with cITP $[16,17]$. The type of pancreatitis was not specified, but careful postmarketing surveillance for the ADR pancreatitis in patients treated with eltrombopag is mandatory.

Complications of p-AIP include failure of exocrine $(16 \%$ of patients) and endocrine ( $11 \%$ of patients) pancreas function $[6,7]$. In our patient, exocrine pancreas insufficiency was fully reversible, and early diagnosis and therapy as reported herein may have contributed to this favorable outcome.

Clinicians should be aware of the co-occurrence of cITP and p-AIP. Abdominal pain and obstructive jaundice are suggestive for p-AIP. Imaging studies and laboratory investigations can help to quickly establish the diagnosis, and therapy with steroids typically induces remission.

Acknowledgements The research was funded by the Österreichische Kinderkrebshilfe (KB and LK). We thank the patient and his parents for their cooperation.

Funding Open access funding provided by Medical University of Vienna.

Author contributions HK, WN, and LK designed the study and wrote the manuscript; $\mathrm{AV}, \mathrm{CZ}$, and $\mathrm{WDH}$ performed gastroenterology diagnostics and therapy and manuscript editing; WK \& KL performed radiological diagnostics and manuscript editing; KW and JS performed histopathology and manuscript editing; KB performed immunological panel screen diagnostics and manuscript editing.

\section{Declarations}

Conflict of interest Leo Kager received advisory board expenses from Bayer, Novartis and Amgen. Hubert Kogler, Wolfgang Novak, Andreas Vécsei, Christina Zachbauer, Wolf-Dietrich Huber, Wolfgang Krizmanich, Karoly Lakatos, Katharina Woeran, Judith Stift and Kaan Boztug declare that they have no conflict of interest.

Human Rights This study has been performed in accordance with the ethical standards laid down in the 1964 Declaration of Helsinki and its later amendments.

Informed Consent Informed consent was obtained from all patients for being included in the study.

Open Access This article is licensed under a Creative Commons Attribution 4.0 International License, which permits use, sharing, adaptation, distribution and reproduction in any medium or format, as long as you give appropriate credit to the original author(s) and the source, provide a link to the Creative Commons licence, and indicate if changes were made. The images or other third party material in this article are included in the article's Creative Commons licence, unless indicated otherwise in a credit line to the material. If material is not included in the article's Creative Commons licence and your intended use is not permitted by statutory regulation or exceeds the permitted use, you will need to obtain permission directly from the copyright holder. To view a copy of this licence, visit http://creativecommons.org/licenses/by/4.0/.

\section{References}

1. Kuhne T. Diagnosis and management of immune thrombocytopenia in childhood. Hamostaseologie. 2017;37:36-44.

2. Cheung E, Liebman HA. Thyroid disease in patients with immune thrombocytopenia. Hematol Oncol Clin North Am. 2009;23:1251-60.

3. Ito A, Yoshizawa K, Fujimori K, et al. Autoimmune hepatitis associated with immune thrombocytopenic purpura. Intern Med. 2017;56:143-7.

4. Olen O, Montgomery SM, Elinder G, et al. Increased risk of immune thrombocytopenic purpura among inpatients with coeliac disease. Scand J Gastroenterol. 2008;43:416-22.

5. Cines DB, Bussel JB, Liebman HA, et al. The ITP syndrome: pathogenic and clinical diversity. Blood. 2009;113:6511-21.

6. Scheers I, Palermo JJ, Freedman S, et al. Autoimmune pancreatitis in children: characteristic features, diagnosis, and management. Am J Gastroenterol. 2017;112:1604-11.

7. Scheers I, Palermo JJ, Freedman S, et al. Recommendations for diagnosis and management of autoimmune pancreatitis in childhood: consensus from INSPPIRE. J Pediatr Gastroenterol Nutr. 2018;67:232-6.

8. Lee HM, Deheragoda M, Harrison P, et al. Autoimmune pancreatitis in children: a single centre experience in diagnosis, management and long term follow up. Pancreatology. 2019;19:169-76.

9. Shimosegawa T, Chari ST, Frulloni L, et al. International consensus diagnostic criteria for autoimmune pancreatitis: guidelines of the International Association of Pancreatology. Pancreas. 2011;40:352-8.

10. Erman B, Bilic I, Hirschmugl T, et al. Investigation of genetic defects in severe combined immunodeficiency patients from turkey by targeted sequencing. Scand J Immunol. 2017;85:227-34.

11. Sakiyama C, Sullivan S. IgG4-related pancreatitis and immune thrombocytopenia: a case report and literature review. Cureus. 2017;9:e1724.

12. Culver EL, Sadler R, Simpson D, et al. Elevated serum IgG4 levels in diagnosis, treatment response, organ involvement, and relapse in a prospective IgG4-related disease UK cohort. Am J Gastroenterol. 2016;111:733-43.

13. Kobayashi S, Yoshida M, Kitahara T, et al. Autoimmune pancreatitis as the initial presentation of systemic lupus erythematosus. Lupus. 2007;16:133-6.

14. Ehrlich LA, Kwitkowski VE, Reaman G, et al. U.S. Food and Drug Administration approval summary: eltrombopag for the treatment of pediatric patients with chronic immune (idiopathic) thrombocytopenia. Pediatr Blood Cancer. 2017;64:e26657.

15. Grainger JD, Locatelli F, Chotsampancharoen T, et al. Eltrombopag for children with chronic immune thrombocytopenia (PETIT2): a randomised, multicentre, placebo-controlled trial. Lancet. 2015;386:1649-58.

16. Gonzalez-Lopez TJ, Alvarez-Roman MT, Pascual C, et al. Use of eltrombopag for secondary immune thrombocytopenia in clinical practice. Br J Haematol. 2017;178:959-70.

17. Moulis G, Bagheri H, Sailler L, et al. Are adverse drug reaction patterns different between romiplostim and eltrombopag? 20092013 French PharmacoVigilance assessment. Eur J Intern Med. 2014;25:777-80.

Publisher's Note Springer Nature remains neutral with regard to jurisdictional claims in published maps and institutional affiliations. 